\title{
EXCAVACIONS AL CASTELL DE LA SUDA DE TORTOSA
}

\author{
Per \\ ALBERT CURTO HOMEDES \\ ANA LORIENTE PEREZ \\ CHARO MARTINEZ LANDIN \\ ELISA ROS BARBOSA
}

Durant el passat mes d'agost de 1984 es portaren a terme al castell de "La Suda» de Tortosa unes excavacions arqueològiques que s'inclouen dins del Pla contra l'Atur que organitza la Generalitat de Catalunya. L'indret escollit es troba adosat a l'edifici de l'antic Palau Reial -actualment Parador Nacional de Turisme- i. tallat per una muralla lateral de la fortalesa. L'interés de l'excavació venia donat per haver-hi descobert en fer-se les obres de l'esmentat parador una tomba exempta $i$ una làpida funèraria àrab del segle $X$. Així doncs el que es pretenia era anivellar l'entorn d'aquesta tomba $i$ entendre millor el seu context.

El resultat ha estat força positiu. Els primers nivells han estat molt fértils tant en ceràmica comú, com de luxe d'època musulmana, si bé amb fragments molt esmicolats i totalment barrejats. Es tractava d'una capa de reomplert portada possiblement d'altres llocs no molt distants, del mateix castell. Han aparegut també restes d'estructures diverses, algunes d'elles de funcionalitat encara no ben definida. D'altres denoten restes del que podrien ben ser tombes malmeses, on encara s'hi conserven fragments d'estuc de color vermell.

Coincidint amb la notable disminució de material, a uns $40 \mathrm{~cm}$. del nivell original, a la zona sud de la tomba exempta es localitzà un primer nivell d'enterraments, amb les restes de 6 ossamentes humanes. Es tracta d'esquelets sense cap mena de sepultura, amb un estat de conservació molt deficient i no tots sencers, ja que concretament alguns havien estat trossejats en les obres del parador. Eren orientats N-S amb el cap girat cap el seu costat dret, és a dir cap a l'E. La seva posició és horitzontal, d'esquena a terra, amb l'excepció de dos cadàvers infantils, que eren posats de costat i lleugerament corbats. Així mateix els braços es troben creuats davant la pelvis. Cal destacar la troballa d'una punta de fletxa entre les coste- 
lles d'un d'aquests morts, l'estudi de la qual ens aportarà valuoses dades cronològiques.

Un parell més d'esquelets aparegueren a nivells una mica inferiors a la zona $W$ del jaciment, de mateixes característiques, però en posició lateral. El que si podriem considerar com un nou nivell d'enterraments són els que es localitzaren gairebé al mateix pla del repeu de la tomba exempta, al seu costat esquerre, disposats paral.lelament. Es tracta de tres enterraments amb sepultures antropomorfes de costats arrodonits -vulgarment conegudes com «de banyera»- fetes de morter. Una d'aquestes es força malmesa, conservant-se només un dels seus costats laterals. Les altres dues en bon estat de conservació pertanyen a una sepultura d'adult i l'altra d'infant. Els morts es trobaven de costat, mirant a l'Est, i amb els braços creuats davant la pelvis.

Un cop anivellat l'entorn de la tomba exempta s'ha deixat, en principi, per acabada l'excavació, si bé els estrats arqueològics vản encara més avall. Es procedí igualment a la neteja i excavació de l'esmentada tomba, ja mig estroncada. Té una planta rectangular i una secció semicircular. Es troba allisada i recoberta d'un estuc vermell, memtre que el seu interior és un veritàble túmul de pedres i còdols units amb morter. La sepultura propiament dita ven donada per dos rengleres de lloses disposades de forma vertical, però que només empren $2 / 3$ parts de la tomba, la resta és només un afegit reomplert unicament de terra. S'han trobat les restes d'un esquelet totalment esmicolat, pero que sembla correspondre a una persona molt vella.

Les conclusions d'aquesta excavació són, ara per ara, difícils de concretar, en trobar-se encara en una etapa d'estudi. Sembla ser, però que es tracta un cementiri musulmà que abraça un periode que va des de l'època califal fins la reconquesta cristiana. Tant la tomba exempta com les antropomorfes pertenyarien a segle $X$-si bé no coetànies-, mentre que el que haviem anomenat el primer nivell d'enterrament seria del segle XII. Esperem que l'estudi antropològic dels ossos ens aportin dades interessants que corrobararan l'estudi que s'està portant ara a terme.

\section{EPITAFI A AL-JĀZIN AL-QA'ID}

En el nom de Deú, clement i misericordiós. No hi ha altre Déu que Alläh, l'únic i sense igual. Déu beneeixi a Mahoma el seu servent i missatger.

Aquesta és la tomba de al-Jāzin al-Qā'id 'Abd al-Salām bn 'Abd Allāh bn Basil que confesava: No hi ha Déu sino Allāh, l'únic i sense igual, Ma homa és son servent i missatger; el Paradís és veritat; el foc és cert «no hi ha dubte que l'hora ve i Déu resucitará als que son en els sepulcres» (1).

Va morí -Déu tingui compassió d'ell- la nit del dilluns quedant catorze nits del Du-1-Qa'da de l'any trescents quaranta nou (nit del diumenge al dilluns 7 de gener del 961 J.C.).

(1) Quran, XXIII, 7. 
Identificació, transcripció i traducció de M. Cruz Hernández, M. Ocaña Giménez, C. Vázquez de Benito i J. Masip i Fonollosa.

\section{Excavacions a la Plaça de la Olivera de Tortosa}

La Plaça de Nostra Senyora de la Cinta, dita també de l'Olivera, es una petita plaça situada al centre de Tortosa, enfront mateix del claustre de la catedral, on ja s'havien realitzat uns sondeijos el propassat any que posaren de manifest una gran potència estratigràfica d'aproximadament 6 metres: des d'època romana fins al moment actual.

Enguany l'existència del ja esmentat Pla de l'Atur, ha permès excavar en extenció en aquesta plaça i portar a terme diversos sondeijos en altres punts del casc antic de la ciutat (Parking, Pont de Barques, Sinagoga i Costa de Capellans), alguns del quals han corroborat l'estratigrafia obtinguda a la Plaça.

L'area excavada a la Plaça de l'Olivera presenta unes dimensions de $20 \times 4$ mts. que metodològicament ha estat dividida en cinc cales de $4 \times 4$ mts.

A continuació exposem sumariament els quatre apartats en que hem agrupat els diferents estrats que apareixen en aquest jaciment:

a) Dels nostres dies fins época baix medieval. Correspòn al primer metre de profunditat respecte al sòl actual $\mathrm{i}$ apareix molt remogut per les constants remodelacions urbanes.

b) Cultura musulmana. Segles X-XII. Aquest periode será el motiu d'aquesta nota preliminar. Apareix a una profunditat de 1 metre a 1 ' $70 \mathrm{mts}$. mts.).

c) Transició: d'època musulmana a tardo-romana $\{1 ' 71$ - 2'60/2'70

d) Romà. De 2'61/2'71 mts. a 5'50 mts. de profunditat on es superposen els diferents moments d'habitació des del s. I d.C. a època tardoromana.

El nivell musulmà posseeix gran abundància de materials ceràmics que per les seves característiques es poden agrupar en:

- Ceràmica comú: Ceràmica de cuina de superficies amb o sense vidriat, de color groc-melòs, verd, irisat i axocolatat que correspòn a formes de gerretes, olles $i$ cassoles. Trespeus. Les tapadores solen ser de forma cóncava amb base plana i agafador central, no obstant n'hi han també de forma cónica amb agafador a la part superior ì peu anular. Les llànties son de bec i poden portar un revestiment vidriat o bé decoració pintada.

- Recipents d'enmagatzenament (gerres i tines). A aquest tipus correspondría un fragment amb decoració epigràfica impresa.

- Caduis de fons pla i piriformes.

- Les formes obertes com ataifors, safes i bols poden presentar vi- 
driats per una o ambdues cares, vidriats amb decoració betejada en negre a l'interior o esmaltats.

- La decoració pintada al manganès apareix en gerres i presenta motius lineals moltes vegades aplicats sobre una engalba de tonalitat clara.

- Han aparegut alguns vasos de cos globular i coll allargat, cilíndric o troncoconic, de parets molt fines, pasta depurada de tons ocre o beix i superficies totalment recobertes per pintura roja, que recorden a formes metàlliques.

- En quant a la ceràmica de luxe amb decoració de rimes vidriades, encara que abundant, apareix quasi sempre molt fragmentada. Els temes més usualment representats son les métopes, els escaquejats, dents de llop, bandes horitzontals, altres motius geométrics i temes vegetals. Les formes que s'han pogut reconstruir corresponen a gerres de dues nances, algunes d'elles amb filtre a l'interior, gerretes, botelles i pitxers.

Finalment cal mencionar un únic fragment de ceràmica amb decoració esgrafiada.

A partir de 1'71 mts. de profunditat s'aprecia una forta disminució en el volum del material, amb la desaparició de les rimes vidriades i vidriats, com així mateix un canvi en les pastes i les formes que pertanyen ja al moment de transició.

D'època musulmana ha aparegut un edifici de notables dimensions $\left(10^{\prime} 80 \mathrm{mts} . \times 3^{\prime} 40 \mathrm{mts}\right.$.), de forma rectangular, dividit en quatre trams iguals per tres envans i flanquejat a ambdós extrems per una canalització.

En la construcció d'aquest edifici es poden diferenciar diversos moments. Al moment inicial correspondrien els murs externs, d'una amplada de $0^{\prime} 50$ mts., construits amb una técnica de «opus spicatum» trabat amb morter que ens situaría en el segle $X$. Un segòn moment ve donat per la construcció dels envans que divideixen la nau en quatre habitacions quadrangulars de $2.40 \times 2.40 \mathrm{mts}$. Aquests paraments estan formats per una única alineació de blocs lleugerament retocats d'aproximadament $20 \times 15$ $\times 8 \mathrm{cms}$. Durant una altre fase constructiva pel costat est s'adossà al mur de tancament de l'edifici, una canalització de forma trapezoidal, de 1'40 mts. d'amplada máxima i o'90 mts. de mínima, amb un canaló de 0'60 mts. Una segona canalització de 1'30 mts. d’amplada i canaló de 0’30 mts., talla l'extrem oest de l'esmentat edifici. Una tercera, perpendicular a l'anterior enllaça per mitjà d'una tubería de ceràmica.

Un darrer moment es representat per l'aixecament de nous murs sobre els murs longitudinals anteriors; la técnica utilitzada per aquests últims es molt més grollera, sensa massa selecció en les dimensions dels blocs de pedra, practicament sense retocar.

Un altre aspecte important a destacar es l'existència d'una mena de fossa a la part occidental de l'edifici que talla el mur longitudinal i en la qual s'hi abocaren les restes humanes de nou individus, actualment en es- 
tudi en el Museu Arqueològic de Barcelona. Junt amb aquests individus s'han trobat anelles de bronze, algunes amb un penjollet i dues petites fíbules. També han aparegut associades amb els esquelets dues monedes en curs d'estudi, d'una de les quals podem avençar que correspòn als comtes Ramón Berenguer II o Berenguer Ramón. Al voltant també hi havien gran quantitat de claus de ferro, un pic i dues aixades.

Com ja s'ha dit ens trobem a l'inici de l'estudi després de set mesos d'excavació continuada, per la qual cosa no podem apuntar dades concluyents. De totes maneres el que sí s'evidencia es que l'edifici avans descrit no respòn ni per les seves dimensions ni característiques a una simple vivenda, sino que sembla tenir un caràcter públic, si bé la seva funció ens és desconeguda.

Cal també fer notar que és dispossa de dos aspectes ben diferenciats (ciutat-necropolis) d'un mateix període cronològic (segles $X-X I I)$ que permet deduir l'importància que tingué Tortosa dins del mòn musulmà com a ciutat fronterera de la Marca Superior, fet que ja es preveia però del qual no hi havia constància arqueològica. 